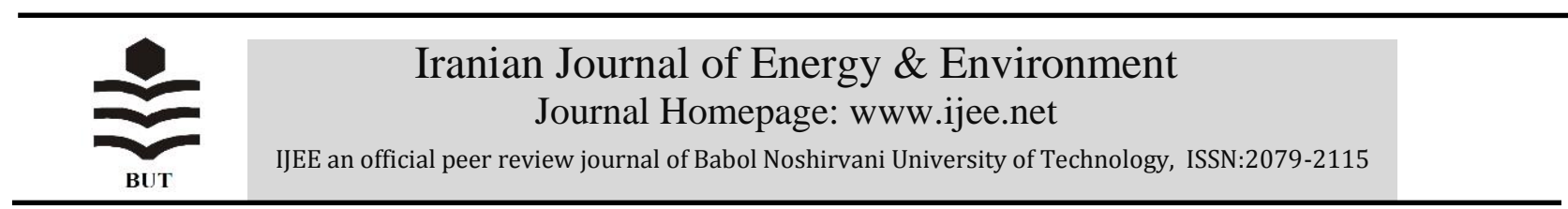

\title{
Electrical Energy Auditing by Analyzing End-Use Energy Consumption: A Case Study of an Office Building in Tehran
}

\author{
M. Tayari ${ }^{*}$ and E. Burman ${ }^{2}$ \\ ${ }^{1}$ School of Chemical Engineering, College of Engineering, University of Tehran, Tehran, Iran \\ ${ }^{2}$ Institute for Environmental Design and Engineering, University College London (UCL), London, England
}

\section{$P A P E R \quad I N F O$}

\section{Paper history:}

Received 07 Augest 2018

Accepted in revised form 21 October 2018

\section{Keywords:}

Electrical energy auditing

Off-Peak

Mid-Peak

On-Peak

Benchmarking

\section{$A \begin{array}{lllllllllll}A & S & T & A & A & T\end{array}$}

Auditing electrical energy in buildings is a feasibility study consisting of a comprehensive assessment of a building's electrical utilities in order to optimize energy consumption. In this paper a bottom-up method to estimate electrical loads is formulated that could help in disaggregating electricity use to specific end-uses in the absence of sub-meters in existing buildings. This method can be used for detailed benchmarking and identification of improvement opportunities. Implementation of the method in an office building, located in Tehran, showed a satisfactorily match $(94.66 \%$ for off-peak, $88.69 \%$ for mid-peak and $94.46 \%$ for on-peak) exists between the calculated loads with the data extracted from electricity bills. The building electrical energy auditing showed a maximum share of consumption for office equipment (32\%) and a lower consumption for lighting (28\%), space heating and cooling $(17 \%)$, domestic hot water $(12 \%)$ followed by catering and other electricity end-uses (11\%). Through interpreting the energy auditing results, strategies for increasing energy efficiency has been suggested.

doi: 10.5829/ijee.2018.09.03.01

\section{INTRODUCTION}

The term carbon footprint, as the total emissions of greenhouse gases expressed as carbon dioxide equivalent, has appeared in recent years with the rise of concerns about climate change. An increase in greenhouse gas productions, and consequently in carbon footprint, is the main event associated with climate change that has led to global warming. Scientists predicted emissions of $\mathrm{CO}_{2}$ and other greenhouse gases from human activities will increase global temperatures by 1.5 to $5.5^{\circ} \mathrm{C}$ during the current century which will result in rising sea levels, frequent floods and droughts [1]. Consequently, efforts should be focused on reducing carbon footprint of all sectors to preserve the planet. Building sector is a key contributor to global carbon emissions. Carbon footprint of a building is defined as the carbon released by the building equivalent of the building's total energy consumption. This is a measurement of the volume of greenhouse gases, caused by activities such as heating, cooling, lighting, catering and other form of energy consumption in a building [2]. Statistics showed building sector in the United States consumes $70 \%$ of the electricity load and accounts for $39 \%$ of carbon dioxide $\left(\mathrm{CO}_{2}\right)$ emissions per year which is more than any other sector. Since buildings have an average lifetime of 50-100 years during which they repeatedly consume energy and produce $\mathrm{CO}_{2}$, if half of the new commercial buildings were built or changed to use $50 \%$ less energy, it would save over 6 million metric tons of $\mathrm{CO}_{2}$ annually for the life of the buildings [1]. Whilst reducing total energy consumption of buildings (electricity, gas and other fuels) is important in the context of climate change, better understanding of the key drivers of electricity use is crucial. The reason is twofolds: 1) electricity use in most countries has higher carbon intensity than other fuels due to carbon emissions associated with production of electricity in power plants and its distribution, 2) most energy end-uses in a building are electrical and therefore it is important to disaggregate total electricity use to end-uses to identify the energy saving opportunities. Reducing electricity consumption can save both the primary energy usage and $\mathrm{CO}_{2}$ equivalent emissions.

The aim of this paper is to demonstrate how a bottom-up method for disaggregating electricity use in existing buildings with no electrical sub-meters can help the benchmarking process and identification of energy saving opportunities. A case study approach has been used to demonstrate the method and its application.

\section{Background: Energy auditing}

According to Annual Energy Outlook 2015, electricity consumption comprises an increasing share of the world's

\footnotetext{
* Corresponding author: Mahnaz Tayari

E-mail: m_tayari@ut.ac.ir
} 
total energy demand [3]. This rapid consumption rate necessitates an analysis to indicate details about the consumption for reducing energy wastes and understanding what investments should be made to improve energy performance. Similarly, in order to identify the potentials for reducing electricity consumption in a building, it is necessary to audit electricity sinks in that building. Finding end-use energy consumption in a building makes a simple and powerful technique for understanding building performance and help to suggest energy-saving options [4, 5]. Energy auditing, also known as energy assessment, which includes analysis of a building's energy consumption is a challenging work due to numerous parameters such as the dynamic behavior of the weather conditions, building operations and the presence of multiple variables [6]. Nonetheless it can be a very useful method for reducing a building's carbon footprint.

Several methods based on simulations and statistics have been developed in order to estimate energy consumption of a building [7-15]. Difficulties may exist in using computer simulations including the considerable amount of detailed input data and time from even experienced users $[7,8]$. Among various methods, energy auditing is used to describe a wide range of energy studies, many procedures of which have been developed for non-residential buildings. According to the audit methodologies developed in IEA EBC Annex 11 by ASHRAE $[16,17]$, the key objectives of an audit process are as follows:

- Analysis of the building energy and utility data, including analysis of energy bills and the installed equipment;

- Survey of the real operating conditions;

- Understanding of the building behavior and the possible interactions with weather;

- Evaluation of energy conservation measures;

- Estimation of energy saving potential;

- Identification of customer needs and their concerns.

Between the wide ranges of definitions, energy auditing of a building can be defined as a feasibility study that consists of comprehensive assessment of electrical utilities used by the building, in order to achieve the following benefits [18]:

- Identify energy use among the various services and to identify energy saving potential

- Establishing an energy management program for reducing energy waste and therefore energy costs.

Energy auditing reports based on this definition often include estimates of electricity consumption hours for different enduses. These provide an overview of important energy-using areas and help to assess the possible saving of energyefficiency measures [5].

\section{MATERIAL AND METHOD}

\section{The bottom-up approach for energy auditing}

Among the available energy auditing approaches, application of bottom-up methods of estimating energy use, enables end-use consumption to achieve detailed information with reasonable accuracy. This method records the electrical load, usage and end-use type of all energy-consuming equipment and calculates energy consumption for each item. In the calculations, equipment can be classified in main groups such as space heating equipment, cooling equipment, lighting, catering and total energy consumption can be summed by end-use.

Observational studies and building user feedback can be used to estimate the usage hours and usage levels. Finally, to improve the reliability of the calculations, the calculated electrical demand of the building can be compared with its actual demand. The actual electrical demand of the building can be obtained through the building's bills or any available metered information such as utility meters [5].

\section{The case study of an office building in Tehran}

The present study is related to the audit of electrical energy consumption of an office building that belongs to a water and wastewater engineering company which is located in north of Tehran. The main duties and functions handled in this building are the office works related to the urban water supplying and distribution, collection and disposal of wastewater, modification and expansion of water and wastewater network, answering client questions and managing customer complaints, etc. This building is more than 20 years old; it is a double storey building above the ground floor used as first and second floor. As it is shown in Figure 1, white stone and granite are used for exterior design of the building. Other architectural specifications of the building including the area of usable floor, roof, etc. are shown in Table 1.

Electricity and natural gas are the two main sources of energy used in this building. The building uses radiators, air conditioners, and water coolers for heating and cooling purposes. Typically, the heating and cooling set points are 24 and 18 degrees Celsius, respectively. As it is shown in Figure 2 , natural ventilation through the windows is used in the offices, hallways, and staircases. Since all the building windows are single glazed, they have a great loss of energy. However, some parts of the building including archive office and toilets use small ventilation system which is shown in Figure 3.

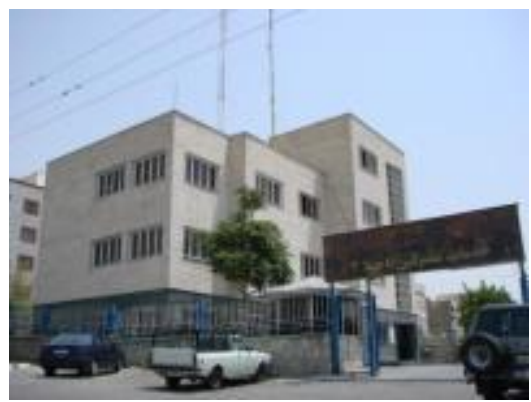

Figure 1. White stone and granite facade office building used as the case study

TABLE 1. Architectural specifications of the building

\begin{tabular}{lc}
\hline Parts of the building & Area (square meters) \\
\hline Usable floor & 810 \\
Roof & 270 \\
The outside walls & 594 \\
Bright walls and windows of the building & 137 \\
Building windows & 129 \\
Building doors & 4 \\
\hline
\end{tabular}



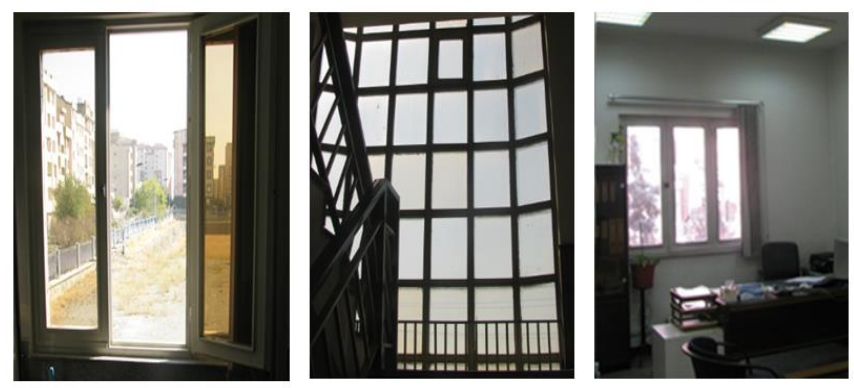

Figure 2. Using natural ventilation through the windows in the hallways, staircases, and offices

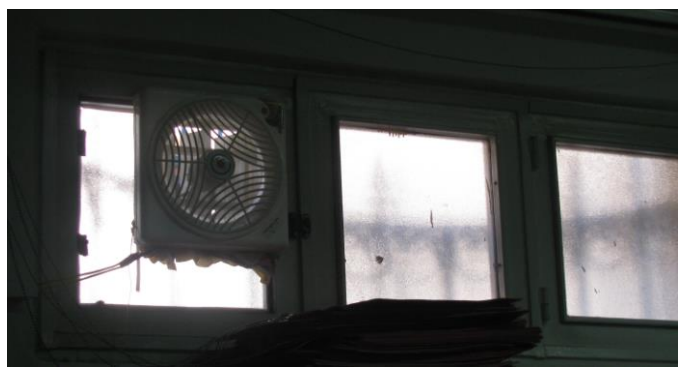

Figure 3. A small ventilation system with poor insulation in the building

\section{Electricity consumption hours and levels}

In order to perform a building energy auditing based on the presented technique, electrical consumers and electrical bills data sheets for the case study were gathered. We considered that the consumers' demands for electricity change seasonally, daily and even hourly. For example, air conditioners are turned on and off seasonally and end-users consume less energy at nights. Electricity consumption can be divided into base load, intermediate load, and peak load consumption. For calculating each consumption, we considered the consumers' demands during 8 hours of the day, on average from 11 P.M. to 7 A.M. as base load demand, 12 hours later i.e. 7 A.M. to 7 P.M. as intermediate load demand, and the 4 remaining hours of the day from 7 P.M. to 11 P.M. as peak load demand. Even though these hours change seasonally, the duration of each load demand category remains constant. The key point is that the cost to provide electricity is different in each load demand category.

\section{Loads and total consumption}

In the first part of this section the bottom-up method for calculation of the base load, intermediate load and peak load of electricity consumption in devices with one electrical consumption power has been presented. The next part describes the method for devices, such as air conditioners, that have one cooling power and one heating power.

We assumed that each device with the electric power of $P_{i}$ is used for $X_{1}$ hours at off-peak times, $X_{2}$ hours at mid-peak times and $X_{3}$ hours at on-peak times during a day. Furthermore, each device is used in $n_{1}$ days of the first month of the year, $n_{2}$ days of the second month and so on in the other months of the year. Usage hours of electrical devices and also usage days were estimated based on the discussion at our meeting with the staffs, building janitors, and security guards. The usage times of air conditioner, office equipment, office lighting, etc. were determined by calculating statistical average of the amounts extracted from surveys filled by a group of 6 staffs which is equivalent to $8 \%$ of the occupants. Likewise, building janitors' opinions were used to estimate the usage hours of catering, cooking, hallways and staircases lighting. Eventually, security guards' viewpoints were gathered to calculate the usage times of yard lighting, remote door opener, and other electrical devices. The amount of energy consumption for all $m$ devices of the same type, at offpeak times, mid-peak times and on-peak times in each month can be written as follows:

$$
\begin{aligned}
& P_{o f f}^{j}=\sum_{i=1}^{m} p_{i} n_{j} X_{i, 1} \\
& P_{\text {mid }}^{j}=\sum_{i=1}^{m} p_{i} n_{j} X_{i, 2} \\
& P_{o n}^{j}=\sum_{i=1}^{m} p_{i} n_{j} X_{i, 3}
\end{aligned}
$$

similarly energy consumption in the respective load demand category duration of the year can be calculated as follows:

$$
\begin{aligned}
& P_{o f f}=\sum_{j=1}^{12} P_{o f f}^{j}=\sum_{i=1}^{m} p_{i}\left(\sum_{j=1}^{12} n_{j}\right)\left(X_{1}\right) \\
& P_{\text {mid }}=\sum_{j=1}^{12} P_{\text {mid }}^{j}=\sum_{i=1}^{m} p_{i}\left(\sum_{j=1}^{12} n_{j}\right)\left(X_{2}\right) \\
& P_{o n}=\sum_{j=1}^{12} P_{o n}^{j}=\sum_{i=1}^{m} p_{i}\left(\sum_{j=1}^{12} n_{j}\right)\left(X_{3}\right)
\end{aligned}
$$

We can apply the last three formulas for all electrical devices except those which have two electrical powers, one for cooling and one for heating which can be different from one another. In this case, we should consider that total consumption is equal to the sum of the cooling consumption in hot months and the heating consumption in cold months of a year. For example assume that an air conditioner is used in $n_{1}, n_{2}$ and $n_{3}$ days of three months of a year for heating purposes, and $n_{10}, n_{11}$ and $n_{12}$ days of three other months of the year for cooling purposes. Then, its electricity consumption during a year will be calculated as follows:

$$
P_{i}=p_{\text {heating }} \sum_{j=1}^{3} n_{j}\left(X_{j, 1}^{\prime}+X_{j, 2}^{\prime}+X_{j, 3}^{\prime}\right)+p_{\text {cooting }} \sum_{j=10}^{12} n_{j}\left(X_{j, 1}^{\prime \prime}+X_{j, 2}^{\prime \prime}+X_{j, 3}^{\prime \prime}\right)
$$

where; $X_{1}^{\prime}, X_{2}^{\prime}, X_{3}^{\prime}$ and $X_{1}^{\prime \prime}, X_{2}^{\prime \prime}, X_{3}^{\prime \prime}$ refers to the off-peak, midpeak and on-peak hours of consumption in the days of the cold months and hot months consecutively. $P_{\text {heating }}$ and $P_{\text {cooling }}$ refers to the heating and cooling power of the air conditioner. Therefore, the amount of energy consumption in off-peak, mid-peak and on-peak times in each month can be calculated as follows:

$$
\begin{aligned}
& P_{\text {off }}^{j}=\sum_{i=1}^{m} P_{\text {off }, i}^{j} \\
& P_{\text {off }}^{j}=p_{\text {heating }} \sum_{j=1}^{3} n_{j} X_{j, 1}^{\prime}+p_{\text {cooling }} \sum_{j=10}^{12} n_{j} X_{j, 1}^{\prime \prime} \\
& P_{\text {mid }}^{j}=\sum_{i=1}^{m} P_{\text {mid }, i}^{j} \\
& P_{\text {mid }}^{j}=p_{\text {heating }} \sum_{j=1}^{3} n_{j} X_{j, 2}^{\prime}+p_{\text {cooling }} \sum_{j=10}^{12} n_{j} X_{j, 2}^{\prime \prime} \\
& P_{\text {on }}^{j}=\sum_{i=1}^{m} P_{\text {on }, i}^{j} \\
& P_{\text {on }}^{j}=p_{\text {heating }} \sum_{j=1}^{3} n_{j} X_{j, 3}^{\prime}+p_{\text {cooling }} \sum_{j=10}^{12} n_{j} X_{j, 3}^{\prime \prime}
\end{aligned}
$$

It is necessary to point out that if the air conditioner is used more than three months for heating or cooling purposes, the amount of $\mathrm{j}$ in these equations increases according to the number of consumption months. 


\section{Detailed analysis of principal end-uses for energy in the building}

Based on the building data sheets gathered through inspection of the facilities and identifying operational and maintenance measures, consumption of principal end-uses (building services, occupiers' equipment, etc.) for energy in the office building are estimated and the percentages of the mentioned consumption are calculated from the obtained data and total consumption.

\section{Evaluation}

To evaluate the method, a series of calculations are performed for the case study. The information from the building's electrical bills during a selected year is shown in Table 2. Daily consumption can be calculated using the data from each bill's duration. Therefore, the consumption in each month is calculated by the sum of its daily consumption. It should be noted that the total consumption in a month can belong to the daily consumption during two or more billing periods.
For example, to calculate the consumption in January, we should consider that 3 days of this month's consumption belong to the 10th bill and 28 remaining days of total 31 days, belong to the 11th bill. The results of these calculations are shown in Tables 3 and 4. Calculation of the electrical load and energy through this method requires preparation a list of all electrical consumers in the building, their electrical power (heating and cooling power if required), their working hours and their working days in each month.

To illustrate, the data sheet of the required information for the duration of March 21 till April 20 is prepared in Table 5. Load consumption will be calculated through equations 8 10. The results of this calculation are available in Table 6 . The same calculations have been done for all months and the results of these calculations have been shown in Table 7 . Using these data, the loads and total consumption of electrical energy for each month were calculated and compared with the amounts calculated from the electricity bills as shown in Figures 4-7.

TABLE 2. Information of the building's electrical energy bills during a selected year

\begin{tabular}{lcccc}
\hline Bill's duration & $\begin{array}{c}\text { Off-peak } \\
\text { consumption (kWh) }\end{array}$ & $\begin{array}{c}\text { Mid-peak } \\
\text { consumption (kWh) }\end{array}$ & $\begin{array}{c}\text { On-peak } \\
\text { consumption (kWh) }\end{array}$ & $\begin{array}{c}\text { Total } \\
\text { consumption (kWh) }\end{array}$ \\
\hline $02 / 17 / 2010$ to 04/12/2010 & 1200 & 1350 & 810 & 3360 \\
$04 / 12 / 2010$ to 05/08/2010 & 560 & 5000 & 380 & 5940 \\
$05 / 08 / 2010$ to 06/07/2010 & 700 & 6300 & 460 & 7460 \\
$06 / 07 / 2010$ to $07 / 05 / 2010$ & 650 & 6800 & 560 & 7870 \\
$07 / 05 / 2010$ to $08 / 11 / 2010$ & 840 & 10900 & 400 & 12300 \\
$08 / 11 / 2010$ to $09 / 07 / 2010$ & 620 & 8300 & 410 & 9320 \\
$09 / 07 / 2010$ to $10 / 05 / 2010$ & 650 & 7500 & 450 & 8560 \\
$10 / 05 / 2010$ to $11 / 02 / 2010$ & 670 & 6100 & 550 & 7220 \\
$11 / 02 / 2010$ to $12 / 04 / 2010$ & 800 & 7400 & 530 & 8750 \\
$12 / 04 / 2010$ to $01 / 04 / 2011$ & 780 & 8800 & 550 & 10110 \\
$01 / 04 / 2011$ to $02 / 05 / 2011$ & 800 & 10600 & 780 & 11950 \\
$02 / 05 / 2011$ to 03/24/2011 & 1120 & 14350 & & 16250 \\
\hline
\end{tabular}

TABLE 3. Daily electrical energy consumption

\begin{tabular}{|c|c|c|c|c|c|}
\hline \multirow[t]{2}{*}{ Bill's duration } & \multirow{2}{*}{$\begin{array}{c}\text { Number of days during bill's } \\
\text { period }\end{array}$} & \multicolumn{4}{|c|}{ Daily consumption (kWh) } \\
\hline & & Off-peak & Mid-peak & On-peak & Total \\
\hline $02 / 17 / 2010$ to $04 / 12 / 2010$ & 54 & 22.2222 & 25 & 15 & 62.2222 \\
\hline $04 / 12 / 2010$ to $05 / 08 / 2010$ & 26 & 21.53846 & 192.3077 & 14.61538 & 228.4615 \\
\hline $05 / 08 / 2010$ to $06 / 07 / 2010$ & 30 & 23.33333 & 210 & 15.33333 & 248.6667 \\
\hline $06 / 07 / 2010$ to $07 / 05 / 2010$ & 28 & 23.21429 & 242.8571 & 15 & 281.0714 \\
\hline $07 / 05 / 2010$ to $08 / 11 / 2010$ & 37 & 22.7027 & 294.5946 & 15.13514 & 332.4324 \\
\hline $08 / 11 / 2010$ to $09 / 07 / 2010$ & 27 & 22.96296 & 307.4074 & 14.81481 & 345.1852 \\
\hline $09 / 07 / 2010$ to $10 / 05 / 2010$ & 28 & 23.21429 & 267.8571 & 14.64286 & 305.7143 \\
\hline $10 / 05 / 2010$ to $11 / 02 / 2010$ & 28 & 23.92857 & 217.8571 & 16.07143 & 257.8571 \\
\hline $11 / 02 / 2010$ to $12 / 04 / 2010$ & 32 & 25 & 231.25 & 17.1875 & 273.4375 \\
\hline $12 / 04 / 2010$ to $01 / 04 / 2011$ & 31 & 25.16129 & 283.871 & 17.0967 & 326.129 \\
\hline $01 / 04 / 2011$ to $02 / 05 / 2011$ & 32 & 25 & 331.25 & 17.1875 & 373.4375 \\
\hline $02 / 05 / 2011$ to $03 / 24 / 2011$ & 47 & 23.82979 & 305.3191 & 16.59574 & 345.7447 \\
\hline
\end{tabular}


TABLE 4. Monthly load consumption of electrical energy from the building's electrical energy bills

\begin{tabular}{|c|c|c|c|c|}
\hline Months & Off-peak (kWh) & Mid-peak (kWh) & On-peak (kWh) & Total (kWh) \\
\hline January & 775.48 & 10126.61 & 532.54 & 11434.64 \\
\hline February & 671.91 & 8652.66 & 467.04 & 9791.62 \\
\hline March & 688.88 & 775 & 465 & 1928.88 \\
\hline April & 653.67 & 3928.84 & 442.69 & 5025.21 \\
\hline May & 710.76 & 6386.15 & 470.30 & 7567.23 \\
\hline June & 697.14 & 7088.57 & 452 & 8237.71 \\
\hline July & 705.83 & 8925.48 & 468.64 & 10099.96 \\
\hline August & 709.24 & 9401.50 & 462.46 & 10573.21 \\
\hline September & 694.92 & 8273.01 & 440.31 & 9408.25 \\
\hline October & 738.92 & 6953.57 & 492.5 & 8185 \\
\hline November & 748.92 & 6924.10 & 514.50 & 8187.54 \\
\hline December & 779.51 & 10126.61 & 530.27 & 11436.4 \\
\hline Total & 8575.24 & 87562.14 & 5738.29 & 101875.7 \\
\hline
\end{tabular}

TABLE 5. Monthly consumption of the building

Device

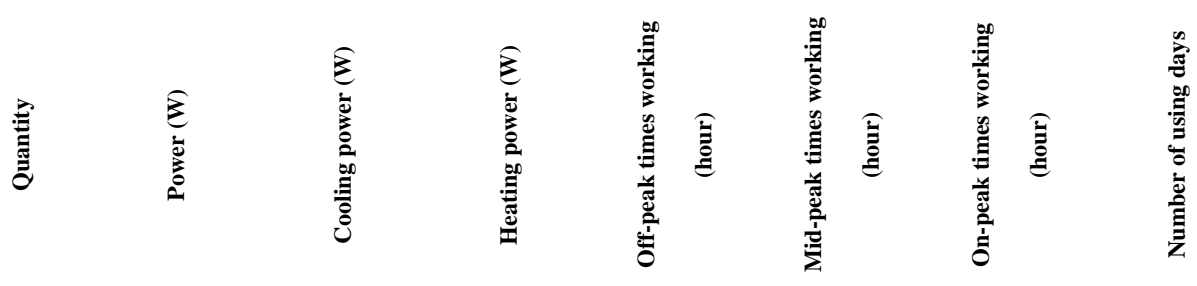

\begin{tabular}{|c|c|c|c|c|c|c|c|c|}
\hline Fluorescent tube $(4 * 18)$ & 30 & 120 & 0 & 0 & 0 & 8 & 0 & 16 \\
\hline Fluorescent tube $(2 * 36)$ & 36 & 100 & 0 & 0 & 0 & 8 & 0 & 16 \\
\hline Fluorescent tube $(3 * 36)$ & 36 & 150 & 0 & 0 & 0 & 8 & 0 & 16 \\
\hline Fluorescent tube $(4 * 36)$ & 10 & 200 & 0 & 0 & 0 & 8 & 0 & 16 \\
\hline CFL bulb & 30 & 20 & 0 & 0 & 0 & 8 & 0 & 16 \\
\hline Projector & 6 & 60 & 0 & 0 & 8 & 0 & 4 & 16 \\
\hline Decorative lamp & 8 & 40 & 0 & 0 & 8 & 0 & 4 & 16 \\
\hline Computer & 40 & 370 & 0 & 0 & 0 & 8 & 0 & 16 \\
\hline Lap top & 10 & 50 & 0 & 0 & 0 & 8 & 0 & 16 \\
\hline Copiers & 4 & 1000 & 0 & 0 & 0 & 0.3 & 0 & 16 \\
\hline Printer & 10 & 200 & 0 & 0 & 0 & 0.35 & 0 & 16 \\
\hline Server & 1 & 670 & 0 & 0 & 8 & 12 & 4 & 31 \\
\hline Water cooler & 5 & 430 & 0 & 0 & 0.2 & 1 & 0.2 & 16 \\
\hline Samovar & 3 & 1400 & 0 & 0 & 0.5 & 2.5 & 0.5 & 16 \\
\hline Refrigerator & 5 & 150 & 0 & 0 & 8 & 12 & 4 & 16 \\
\hline Microwave oven & 3 & 1000 & 0 & 0 & 0 & 0.25 & 0 & 16 \\
\hline Household fan & 3 & 60 & 0 & 0 & 0 & 6 & 0 & 16 \\
\hline Television & 3 & 140 & 0 & 0 & 0 & 8 & 0 & 16 \\
\hline Remote door opener & 2 & 4.5 & 0 & 0 & 8 & 12 & 4 & 31 \\
\hline Air Conditioner(50000Btu/hr) & 1 & 0 & 5004 & 8334 & 0 & 8 & 0 & 0 \\
\hline Air Conditioner(36000 Btu/hr) & 3 & 0 & 3819 & 3920 & 0 & 8 & 0 & 0 \\
\hline Water cooler 5000 & 4 & 0 & 690 & 0 & 0 & 8 & 0 & 0 \\
\hline Double container source pump & 1 & 0 & 0 & 130 & 2 & 8 & 2 & 31 \\
\hline Consumed hot water & 1 & 0 & 0 & 270 & 2 & 8 & 2 & 31 \\
\hline Circulating hot water & 1 & 0 & 0 & 750 & 2 & 8 & 2 & 0 \\
\hline Consumed cool water & 1 & 0 & 0 & 2200 & 2 & 8 & 2 & 31 \\
\hline Torch fan & 1 & 0 & 0 & 370 & 0 & 8 & 0 & 0 \\
\hline
\end{tabular}


TABLE 6. Consumption of electrical devices during March 21 till April 20

\begin{tabular}{|c|c|c|c|}
\hline Device & Off-peak (Wh) & Mid-peak (Wh) & On-peak (Wh) \\
\hline Fluorescent tube (4*18) & 0 & 460800 & 0 \\
\hline Fluorescent tube $(2 * 36)$ & 0 & 460800 & 0 \\
\hline Fluorescent tube $(3 * 36)$ & 0 & 691200 & 0 \\
\hline Fluorescent tube $(4 * 36)$ & 0 & 256000 & 0 \\
\hline CFL bulb & 0 & 76800 & 0 \\
\hline Projector & 46080 & 0 & 23040 \\
\hline Decorative lamp & 40960 & 0 & 20480 \\
\hline Computer & 0 & 1894400 & 0 \\
\hline Lap top & 0 & 64000 & 0 \\
\hline Copiers & 0 & 19200 & 0 \\
\hline Printer & 0 & 11200 & 0 \\
\hline Server & 166160 & 249240 & 83080 \\
\hline Water cooler & 6880 & 34400 & 6880 \\
\hline Samovar & 33600 & 168000 & 33600 \\
\hline Refrigerator & 96000 & 144000 & 48000 \\
\hline Microwave oven & 0 & 12000 & 0 \\
\hline Household fan & 0 & 17280 & 0 \\
\hline Television & 0 & 53760 & 0 \\
\hline Remote door opener & 2232 & 3348 & 1116 \\
\hline Double container source pump & 8060 & 32240 & 8060 \\
\hline Consumed hot water & 16740 & 66960 & 16740 \\
\hline Consumed cool water & 136400 & 545600 & 136400 \\
\hline Sum & 553112 & 5261228 & 377396 \\
\hline
\end{tabular}

TABLE 7. Monthly load consumption of electrical energy from the mentioned method

\begin{tabular}{|c|c|c|c|c|}
\hline Month & Off-peak (kWh) & Mid-peak (kWh) & On-peak (kWh) & Total (kWh) \\
\hline January & 735.04 & 10665.62 & 498.82 & 11899.48 \\
\hline February & 655.48 & 9367.39 & 444.57 & 10467.45 \\
\hline March & 651.77 & 8156.67 & 442.45 & 9250.90 \\
\hline April & 577.15 & 5560.44 & 388.20 & 6525.80 \\
\hline May & 682.96 & 6714.92 & 448.64 & 7846.53 \\
\hline June & 660.93 & 7167.95 & 434.17 & 8263.05 \\
\hline July & 682.96 & 9289.30 & 448.64 & 10420.90 \\
\hline August & 682.96 & 9944.05 & 448.64 & 11075.66 \\
\hline September & 662.37 & 8837.60 & 435.12 & 9935.09 \\
\hline October & 702.04 & 6980.18 & 465.82 & 8148.04 \\
\hline November & 711.33 & 7186.90 & 482.73 & 8380.96 \\
\hline December & 735.04 & 8865.20 & 498.82 & 10099.06 \\
\hline Total & 8140.05 & 98736.27 & 5436.66 & 112312.99 \\
\hline
\end{tabular}




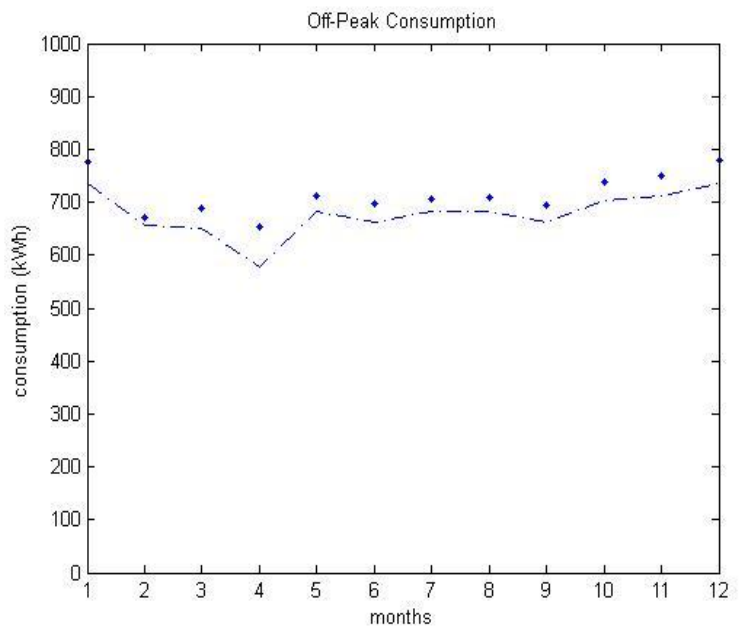

Figure 4. Comparison between electrical energy consumption at off-peak times calculated by the proposed method (dotted line) and the results from electricity bills during a year (represented by diamonds)

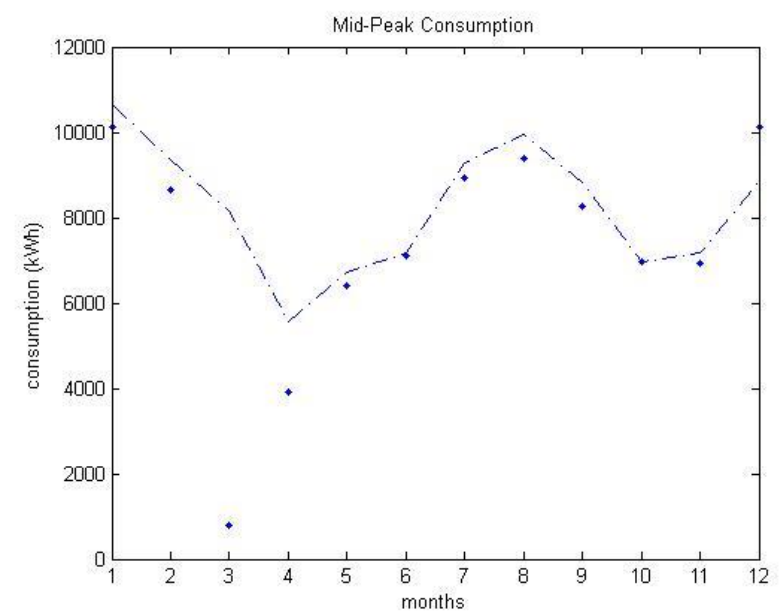

Figure 5. Comparison between electrical energy consumption at mid-peak times calculated by the proposed method (dotted line) and the results from electricity bills during a year (represented by diamonds)

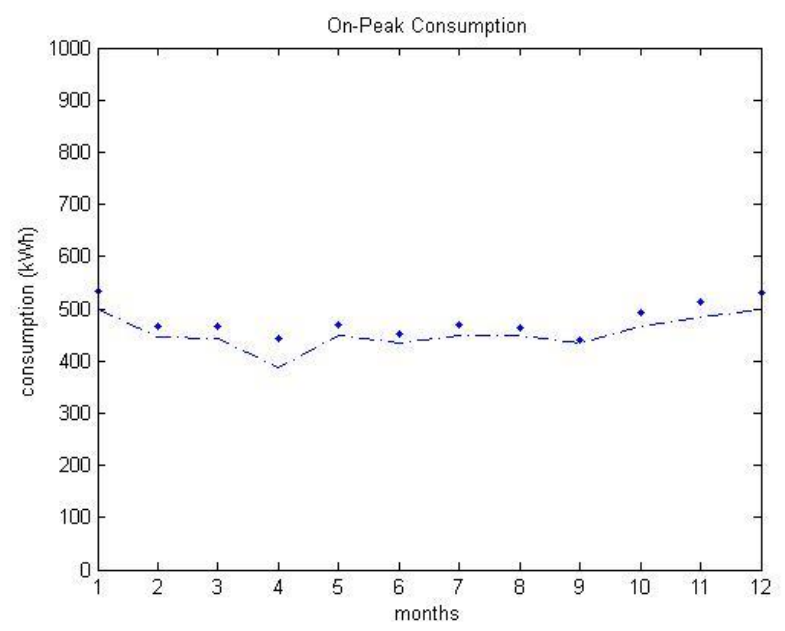

Figure 6. Comparison between electrical energy consumption at onpeak times calculated by the proposed method (dotted line) and the results from electricity bills during a year (represented by diamonds)

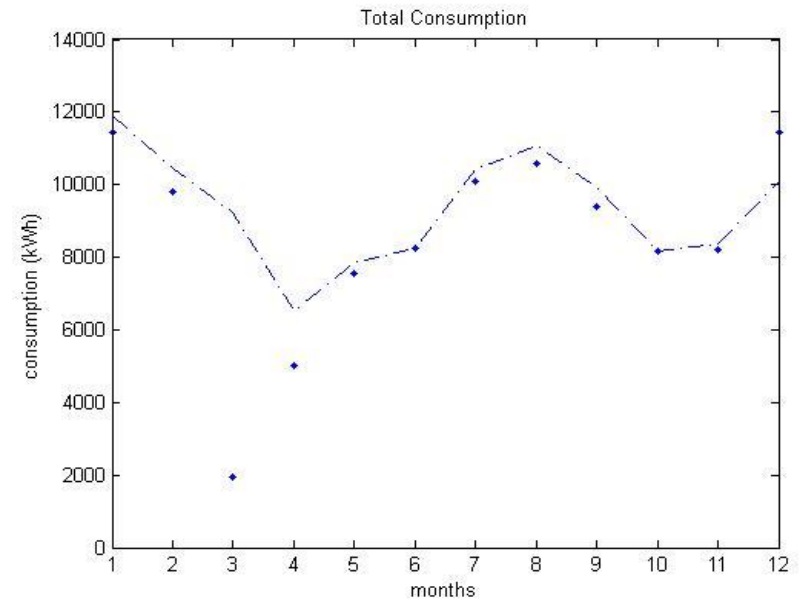

Figure 7. Comparison between total electrical energy consumption calculated by the proposed method (dotted line) and the results from electricity bills during a year (represented by diamonds)

\section{RESULTS AND DISCUSSION \\ Loads consumption}

Percentage of average absolute difference (\%AAD) of these results summarized in Table 8 . The results indicate that the described bottom-up approach can calculate the electrical load and energy with reasonable accuracy. However, it should be noted that part-load efficiency of the equipment was not examined in the current study which is a possible source of error. The current study has only calculated full load operation of the equipment. Figures 4 to 7 show in the month of March real consumption is less than the consumption calculated through the proposed method, with $79.14 \%$ AAD according to the results in Table 8. Consumption deviation in April has the second large \%AAD, with the amount of 22.99. A possible explanation is that March and April include the first month of the Solar Hijri calendar, which include New Year holydays, which affect workings days and also working hours of staffs most of the times. Therefore, the number of the days that each device was used is subject to uncertainty and affected by New Year holidays.

Figures 4 and 6 show the calculated consumption during off-peak and on-peak times are lower than the obtained consumption from the building bills. This can be due to the standby power on appliances which are consumed when switched off or not performing their primary functions. Standby power consumption provides a good opportunity for reducing both energy consumption and greenhouse gas emissions. Increased efficiency of standby modes and subsequent reduction of the overall power demand is achievable through cooperation between the governments, industries, consumers and integrated international policies [19]. The standby power consumption during night mode was highlighted in the International Energy Agency report in 2001 [20]. Raj et al. [19] pointed that as the international community has taken an approach to reduce standby power, consumption can be reduced by an average of $75 \%$ with cost effective design and technological improvements. Saving as high as $90 \%$ can be achieved in many appliances without any reduction in services. Also, Meier presented the importance of conservation of standby power for saving the energy consumed [21]. 
TABLE 8. \%AAD of electrical load calculations

\begin{tabular}{|c|c|c|c|c|c|}
\hline Month & Off-peak & Mid-peak & On-peak & Total & Average \\
\hline January & 5.50 & 5.05 & 6.75 & 3.90 & 5.76 \\
\hline February & 2.50 & 7.63 & 5.05 & 6.45 & 5.06 \\
\hline March & 5.69 & 90.49 & 5.09 & 79.14 & 33.75 \\
\hline April & 13.25 & 29.34 & 14.03 & 22.99 & 18.87 \\
\hline May & 4.07 & 4.89 & 4.82 & 3.55 & 4.59 \\
\hline June & 5.47 & 1.10 & 4.10 & 0.30 & 3.55 \\
\hline July & 3.34 & 3.91 & 4.45 & 3.07 & 3.9 \\
\hline August & 3.84 & 5.45 & 3.07 & 4.53 & 4.12 \\
\hline September & 4.91 & 6.38 & 1.19 & 5.30 & 4.16 \\
\hline October & 5.25 & 0.38 & 5.72 & 0.45 & 3.78 \\
\hline November & 5.28 & 3.65 & 6.58 & 2.30 & 5.17 \\
\hline December & 6.05 & 14.22 & 6.30 & 13.24 & 8.85 \\
\hline Total & 5.34 & 11.31 & 5.54 & 9.29 & 7.39 \\
\hline
\end{tabular}

Finally, Figures 4-7 show that electrical energy consumption in mid-peak times has a maximum share in total usage. The calculated amounts for electrical energy consumption in midpeak times through the method outlined in this paper are higher than the real amounts, obtained from the building electricity bills. One of the reasons for this can be the approximation of the amounts of consumption power considered for each device. It is notable that the more accurate the working times and consumption power, the more accurate results obtained.

\section{End-Uses consumption}

Figure 8 shows auditing of the building electrical energy consumption calculated form Table 6 . The bottom-up method allows total energy consumption of a building to be divided into end-uses. Figure 8 shows consumption of office equipment has the highest share in total consumption (32\%). Using efficient equipment widely depends on the performance requirement, time of using, economical purchasing power and payback time. Depending on the specific function of each business unit, decisions should be made for replacement or elimination of inefficient equipment. Other suggested solutions include unplugging seldom-used applications and using power strips for switching off purposes in order to avoid standby power consumption.

The second share of total consumption belongs to lighting purposes, including official lighting and yard lighting consumption (28\%). In this field upgrading lighting to high efficiency bulbs such as T5 flouresecnt lamps with automated control features including pressence detection and dimming will play an important role since energy efficient lighting uses less energy and generates less heat .

Electrical energy consumption for space heating or cooling purposes (the sum of water coolers consumption and air conditioners consumption) has the third share in total consumption (17\%), so by application of thermal insulation in the building, unwanted heat loss or gain can be reduced and consequently the electrical energy demand will decrease. Temperature control will also be a good measure to save energy as both heating and cooling set points can be adjusted to provide adequate level of thermal comfort whilst saving energy compared to the existing values.

Domestic hot water consumption represents $12 \%$ and catering and other electricity end-uses consumption represents $11 \%$ of total electricity consumption in the building. A possible explanation for these comparatively low percentages is using natural gas as another source of energy for heating, cooking, and supplying hot water. The amount of consumed natural gas over the duration studied in this work which is obtained from the building bills is 24278 cubic meters of which $78 \%$ belong to the heating purposes and $22 \%$ to the cooking and supplying hot water. In general, raising cultural awareness which underlies many of our energy-using activities will play a vital role in reducing these percentages of total consumption.

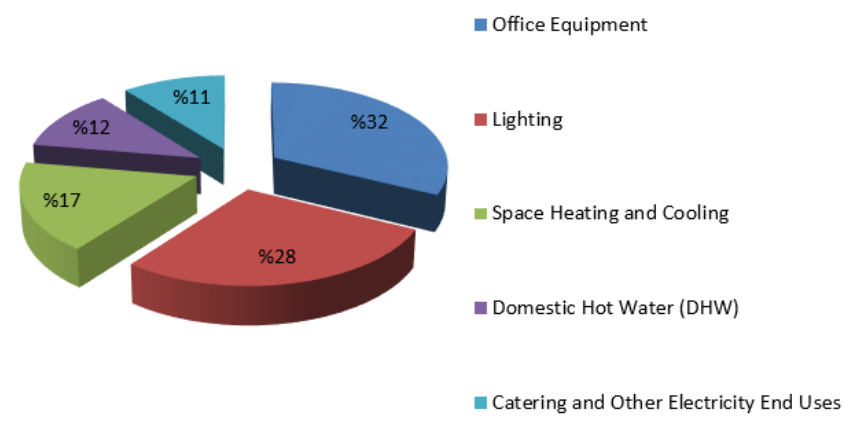

Figure 8 . The results of the electrical energy consumption auditting

\section{Comparison of the results}

With the current increasing demand of electrical energy, there is a growing interest in finding more accurate methods in order to estimate electricity consumption in buildings. Comparison of the results obtained by the applied method with benchmarks and other case studies makes it possible to evaluate the consumption patterns and also the performance of the current method better. 
For example, energy auditing reports in the UK showed that normally in an official building, office equipment loads will represent more than $20 \%$ of the total energy use. According to Energy Consumption Gide (ECG) 19, electricity uses for office equipment ranges from $12 \mathrm{kWh} / \mathrm{m}^{2}$ per year (for good practice case of naturally ventilate cellular type of office buildings) to $32 \mathrm{kWh} / \mathrm{m}^{2}$ per year (in typical case of airconditioned prestige type of office buildings). These consumption values correspondingly represent 36 and $9 \%$ of the total electricity use in each office type [22]. As we can see the share of office equipment use in the current study which represents $32 \%$ of total consumption is close to the value of office equipment use in good practice case of naturally ventilate cellular type of office buildings.

In another case study, auditing energy consumption of an educational building located in hot and humid area, by Sait [23] shows maximum share of consumption for air conditioning $(82.9 \%)$, and a lower consumption for light office equipment, lab devices, other equipment and elevators. Another research by Chirarattananon et al. [24] in three types of buildings including school, city halls and hospitals showed the highest share of consumption for air conditioning systems following by lighting and equipment consumption.

Taken together, good practices studies suggest applying a number of energy-efficient techniques which provide abundant opportunities for reducing energy consumption and costs in all building (new and old) through improving energy efficiency, including [1]

- Incorporating the most efficient heating, ventilation and air conditioning systems, along with operations and maintenance of such systems to assure optimum performance.

- Using state of the art lighting and optimizing daylighting

- Using renewable energy especially solar energy which can be applied in domestic applications

- Implementing proper construction waste management

\section{CONCLUSIONS}

Efficient buildings can play a key role in decreasing $\mathrm{CO}_{2}$ emissions, and energy auditing of a building is the first step in identifying appropriate potentials in order to implement energy efficiency methods. In this paper a bottom-up method to estimate base load, intermediate load, peak load and total consumption of electrical energy is formulated, and a series of calculation for an office building in Tehran was performed to evaluate the method. The results were compared with the data extracted from electricity bills and showed a satisfactorily match with 9.29\%AAD for total consumption (5.34\%AAD for off-peak, $11.31 \%$ AAD for mid-peak and $5.54 \%$ AAD for onpeak). Through the described bottom-up method analysis of total electrical energy consumption in buildings can be easily performed and it is therefore possible to make economic decisions about the optimum time for using each electrical device. Implication of this method brings the possibility of energy auditing for buildings and determination of the amount of energy which can be produced, saved and utilized. Finally, review of building energy auditing results can suggest new strategies for reducing carbon footprints of buildings.

\section{REFERENCES}

1. U.S. Green Building Council (USGBC), Buildings and Climate Change, http://www.eesi.org/files/climate.pdf

2. D. Bouley, Estimating Data Center's Electrical Carbon Footprint, Schneider Electric's Data Center Science Center, http://www.apc.com/salestools/DBOY-7EVHLH/DBOY7EVHLH_R0_EN.pdf

3. U.S. Energy Information Administration, 2015, Annual Energy Outlook with projections to 2040.

4. M. Airaksinen, P. Matilainen, 2011, A Carbon Footprint of an Office Building, Energies 4, 1197-1210.

5. J. Field, J. Soper, P. Jones, W. Bordass, P. Grigg, 1997, Energy performance of occupied non-domestic buildings: Assessment by analysing end-use energy consumptions, Building Services Engineering Research \& Technology, 18. 1, 39-46.

6. N. Fumo, P. Mago, R. Luck, 2010, Methodology to estimate building energy consumption using energy plus benchmark models, Energy and Buildings 42, 2331-2337.

7. Y. Zhu, 2006, Applying computer-based simulation to energy auditing: a case study, Energy and Buildings 38, 421-428.

8. T. Catalina, J. Virgone, E. Blanco, 2008, Development and validation of regression models to predict monthly heating demand for residential buildings, Energy and Buildings 40, $1825-1832$.

9. A. Hernandez, F. A. Sanzovo, Use of simulation tools for managing buildings energy demand. Available from: http://simulationresearch.lbl.gov/EP/ep main.html.

10. F. W. H. Yik, J. Burnett, I. Prescott, 2001, Predicting airconditioning energy consumption of a group of buildings using different heat rejection methods, Energy and Buildings 33, 151166.

11. S. Chirarattananon, J. Taveekun, 2004, An OTTV-based energy estimation model for commercial buildings in Thailand, Energy and Buildings 36, 680-689.

12. Y. Pan, Z. Huang, G. Wu, C. Chen, 2006, The application of building energy simulation and calibration in two high-rise commercial buildings in Shangai, Second National IBPSA-USA Conference.

13. F. Gugliermetti, G. Passerini, F. Bisegna, 2004, Climate models for the assessment of office buildings energy performance, Building and Environment 39, 39-50.

14. F. S. Pedrini, R. Westphal, Lamberts, 2002, A methodology for building energy modelling and calibration in warm climates, Building and Environment 37, 903-912.

15. F. S. Westphal, R. Lamberts, 2005, Building simulation calibration using sensitivity analysis, Ninth International IBPSA Conference.

16. ASHRAE Audit Procedures, 2012, Techstreet.com, Retrieved 03-29.

17. IEA EBC Annex 11, 2012, iea-ebc.org, Retrieved -03-29.

18. http://www.bdg.nus.edu.sg/BuildingEnergy/publication/papers/ BCABEAud.pdf, Retrieved 2014-03-29

19. P. Ajay -D- Vimal Raj, M. Sudhakaran, P. Philomen -D-Anand Raj, 2009, Estimation of Standby Power Consumption for Typical Appliances, Journal of Engineering Science and Technology Review 2. 1, 71-75.

20. International Energy Agency, 2001, Report on things that go blip in the night standby power and how to limit.

21. A. Meier, 1999, Standby power - A quiet use of energy, CADDET Energy Efficiency newsletter, No. 4. 
22. A. C. Menezes, A. Cripps, D. Bouchlaghem, R. Buswell, 2013, Benchmarking small power energy consumption in UK office buildings: a review of data published in CIBSE guide F, Building Services Engineering Research and Technology, 34. 1, 73-86.

23. H. Hussain Sait, 2013, Auditing of energy consumption of an educational building in hot and humid area, Energy Conservation and Management 66, 143-152.
24. S. Chirarattananon, J. Taveekun, 2003, A technical review of energy conservation programs for commercial and government building in Thailand, Energy Conservation and Managment 44, $743-762$.

\section{Persian Abstract}

DOI: 10.5829/ijee.2018.09.03.01

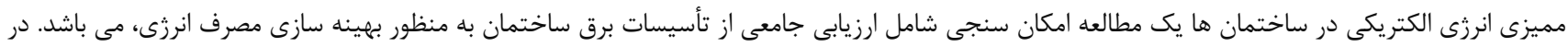

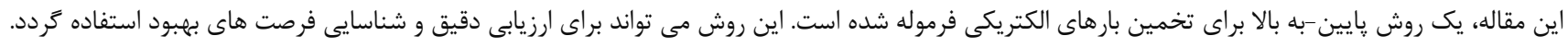

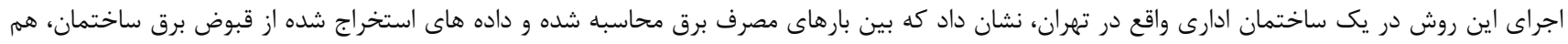

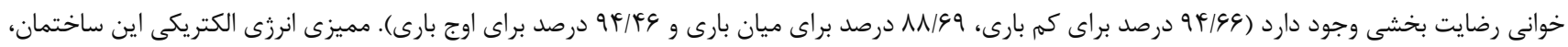

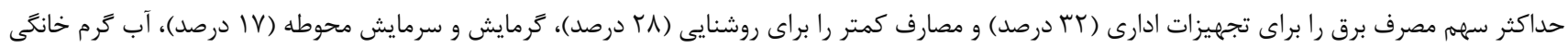

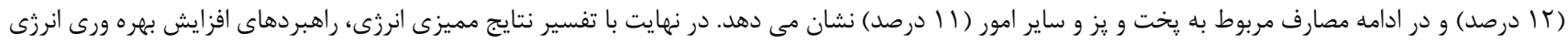

